\title{
Students' Attitudes and Perspectives Towards Using Videos in Technology Assisted English Class
}

\author{
Li Sun \\ School of Foreign Languages \& Cultures, Xiamen University, Xiamen, 361005 China \\ sunli@xmu.edu.cn
}

Keywords: attitude, perspective, video tool, English teaching

Abstract: Expanding frontiers of technology in higher education enables the massive use of multimedia in traditional classrooms. In English classes, instructors tend to use videos as teaching materials to engage students' attention and interest, trying to improve students' learning outcomes eventually. Videos tools poises both opportunities and challenges to teaching and learning, however, its full function as an effective teaching approach has not been realized completely. Based on an survey on English learners in a comprehensive university, this current study focuses on students' attitude and perspectives towards using videos in English classes, including their reasons for supporting or against using video in class; their focus of attention; their preference for the subject matters, durance and subtitles of the videos; their attitude towards activities based on videos, etc. It is hoped that with the findings of this study, instructors may have a better understanding on the needs of students, thus using videos in technology assisted English classes could be more effective and efficient.

\section{Introduction}

In the past decades, technology and multimedia has been massively used in higher education. Language teaching instructors and teachers incline to use multimedia, video in particular as a teaching tool to enrich their teaching tasks and help learners improve their English skills. However, it is found that there are unsolved issues regarding the use of video in class. Instructors select videos without taking students' needs into consideration, thus they become the controller of technical equipment only in a certain task. Lack of background introductions, enhancement of new words and phrases, and effective in-class tasks make playing videos a complete waste of classroom time. Students leaves the classroom without concrete learning outcomes, only fun and relaxing experiences. Teachers should have a better understanding of students' attitude and perspective therefore provide more effective English listening, speaking, reading, writing and translating activities related to the video used in class. Based on a survey, this current research focuses on students' attitude and perspectives towards using videos in English classes, including their reasons for supporting or against using video in class; their focus of attention; their preference for the subject matters, durance and subtitles of the videos; their attitude towards activities based on videos, etc. in order to provide findings for instructors with the preparation of a lesson. 


\section{Using videos in English class}

Videos are able to record physical reality but they are understood differently from ordinary human experiences. There are learner characteristics of video materials as teaching resources summarized by Champoux [1]. In Champoux's study, videos can "Show a viewer something that might go unnoticed with ordinary vision with close-up shot; Show more than what ordinary vision can see with a long shot; Put a series of images together in a unique sequence in-tended to have specific viewer effects with film editing; Show social interaction between two or more parties by switching scenes from a view of one party to a view of the other party to the interaction with shot/reverse-shot; Deliver dialogue, sound and music to a scene's drama, humor, or satire to give desired effects."

These unique characteristics give videos the power to influence people, which audience seldom realize since they usually watch videos as a whole and most of the time viewers are attracted by the story, pictures and characters. When videos are used in classes, for English language teaching in particular, instructors may make full use of the aforementioned unique characteristics to guide students to understand the video better and learn English language more effectively.

Champoux also points out that videos can serve many teaching functions which will work depending on different teaching styles and course goals [2]. He summarizes them in eight "as" phrases with an explanation for each:

1) Film as Case: Scenes from a well-acted and well-directed film present material more dramatically and engagingly than a print case.

2) Film as Experiential Exercise: Framing an experiential exercise around film scenes substitutes active, visual material for a printed exercise.

3) Film as Metaphor: Metaphors often leave lasting impressions that a person easily recalls.

4) Film as Satire: Satire is an effective art form for burning concepts into a person's mind. Well-done satire can leave an unforgettable image of concepts you are trying to teach.

5) Film as Symbolism: Some scenes from films can offer a symbolic way of communicating theories and concepts. Unusual shots, sequencing, lighting, and black and white film often convey symbolism.

6) Film as Meaning: The visual and auditory effects of great films convey a message better than printed or spoken words.

7) Film as Experience: You can use this feature of film to introduce students to other country cultures.

8) Film as Time: Films based on earlier periods can help show aspects of industrial and organizational psychology during an earlier time.

Champoux's summary provides clear implications for using videos as a teaching tool in the EFL classes [2]. Furthermore, using videos as a teaching tool in the EFL classes has plenty of benefits, however, videos are not perfect, nor are they all-powerful teaching tools. It is inevitable that their story, content or pedagogy may have negative effects on the learning process in class. In order to minimize the negative effects and avoid unwanted results, teachers need to be aware of the possible disadvantages. When discussing the positive roles that videos can play, Summerfield (2004) also points out their possible negative effects. Regarding English language teaching and learning, videos might misinform or distort the truth, and even lie; the experience they provide might be superficial; they might cause people to fear, dislike, or minimize human differences; some videos might reinforce ethnocentrism; or reinforce a single perspective; create or reinforce stereotype. As most videos are fictional, students may assume that the world described in the video is real. Actually, it is the world fiction writers and video directors, who have much flexibility in how much reality they want to show, imagine and create. 
Moreover, during the process of watching videos, students are easily distracted by the content of scenes and plots. It might be difficult to accomplish the planned language learning aim while students pay much less attention to the language itself [3].

In addition, using videos in class takes up so much time that other classroom activities cannot be fully performed. Thus, it is the teacher who has to control the timing properly. If too much time is given to watching videos, class time will be used up very quickly and teachers cannot offer enough guidance and help. Besides, students will not have many chances for thinking and discussing, which is one of the most important parts of their learning. Therefore, the choice of videos is also very important. Within a certain time limit, the sections that most efficiently achieve the pedagogical goals should be selected, so they can also warrant the use of class time [4].

Using videos as a teaching tool has been a pedagogical approach widely conducted in English language teaching class throughout China. Hu conducted an attitudinal study on using English videos in class [5]. The subjects are 207 sophomore English learners. This research shows that most students like watching videos in English class. However, the results from the study also reveals that students think videos in class are just for entertainment, and the effects on promoting English skills are rather minimal. As for the reasons, $\mathrm{Hu}$ finds out that the advantages of using videos as a teaching tool have not been realized fully [5]. Most of the time, teachers choose videos freely without concerning the features of the students and only be the equipment controllers. There is not enough background information, sentences understanding or effective activities. Students are distracted by the exciting scenes, fancy settings, fashionable actors and the fictional plot. The planned language learning aim cannot be accomplished while students pay much less attention to the language itself. Students only have fun during the class but do not learn anything. The leading position of teachers is missing because they do not know the demands for students to improve English skills.

\section{Research design}

\subsection{Research questions}

The main research question of this paper is: What are students' attitudes and perspectives towards using videos in English learners' English classes? Guided by the related theories and researches, this study does an attitudinal survey of English learners, including their preference for the content, durance, style and subtitles of the films; their needs of how to participate in the class and finish the assignment; their demands of teachers' help such as introducing the background information, understanding of difficult sentences and related cultural explanation, etc.

\subsection{Subjects}

In this research, the subjects are 100 students from a comprehensive university in China. 50 of the subjects are sophomores, and the other 50 are juniors. All of them have more than seven years' experience of learning English. Therefore, their English language proficiency is at the upper-intermediate level, thus English language is not a barrier for them in understanding videos.

They all have taken more than 10 courses offered or required by the university including Comprehensive Reading, English Writing, Extensive Reading, Oral English, English Listening and History of Western Civilization, etc. Juniors also watch videos in some of their advanced courses, such as Advanced Reading, Audio-visual Comprehension and Analysis, English Language Teaching, History of English Literature, History of American Literature and Selected Reading of American Literature, etc. Videos are commonly used as a teaching tool in their English classes.

This study mainly adopted questionnaires, discussion and interview methods. The questionnaires 
have 14 multiple choice questions, to which more than one alternatives are allowed, and 1 open-ended question. The writer also took 10 students out of these 100 subjects for further discussion and interview. The writer administered the survey among 50 sophomores and 50 juniors in the university. One hundred questionnaires were sent out and all of them were reclaimed. The effective rate was $100 \%$. In order to analyze data, the writer used SSPS to analyze and compare the results.

\subsection{Research method}

This study mainly adopted questionnaires, discussion and interview methods. The questionnaires have 14 multiple choice questions, to which more than one alternatives are allowed, and 1 open-ended question. The writer also took 10 students out of these 100 subjects for further discussion and interview. The writer administered the survey among 50 sophomores and 50 juniors in the university. One hundred questionnaires were sent out and all of them were reclaimed. The effective rate was $100 \%$. In order to analyze data, the writer used SSPS to analyze and compare the results.

\section{Findings and discussions}

\subsection{Students' general attitude towards using videos in the English classes}

Students have different opinions on the question of whether they like or dislike using videos as a teaching tool in English classes. Of all the subjects, 87 students like using videos in class, while 13 students think they dislike it. Figure 1 shows clearly that the method of using videos as a teaching tool in class occupies a dominant position among English learners.

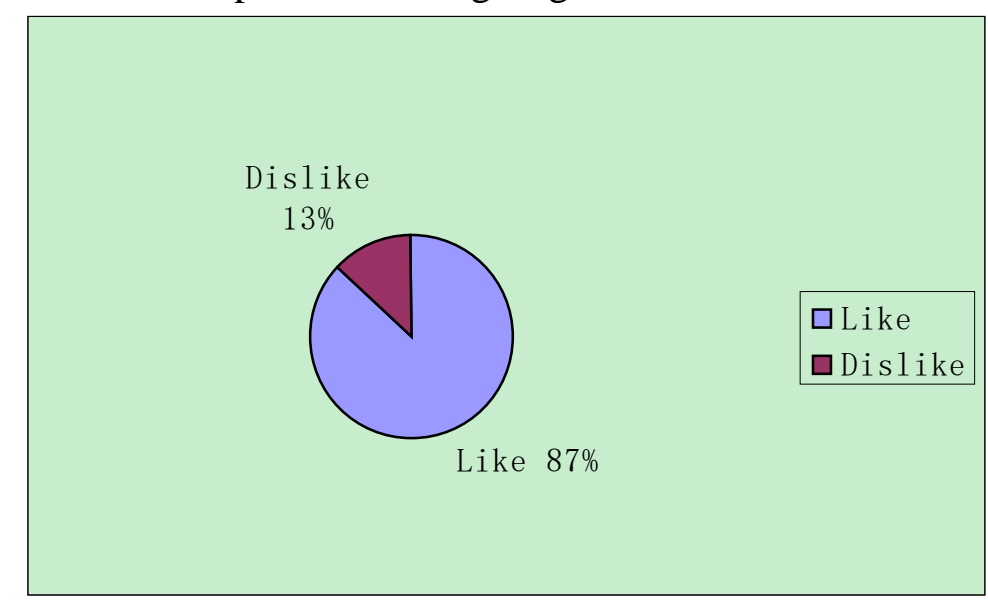

Figure 1. General attitude towards using videos in class

However, whether students like using videos in class or not, they all think it has both advantages and disadvantages. The following parts will give a further discussion.

\subsubsection{Reasons for supporting using videos in the English classes}

$87 \%$ of the one hundred subjects think they like using videos as a teaching tool in English classes. However, they have different reasons for why they like using videos in class. The reasons why students like videos in class are clearly presented in Figure 2. 


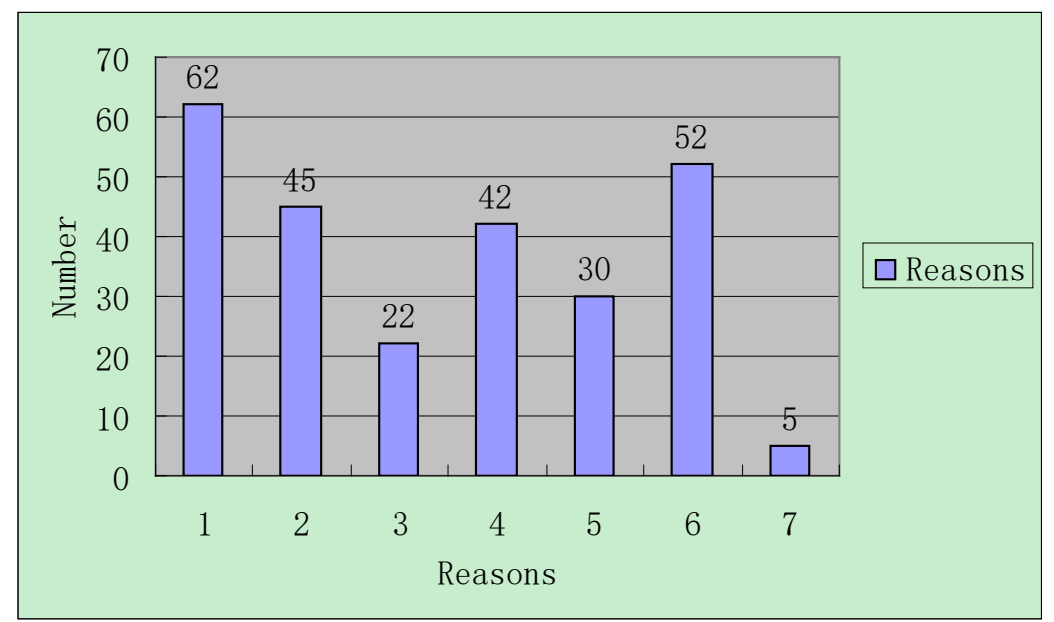

Figure 2. Reasons for supporting using videos in the EFL classes

In the questionnaires, the research designer gives seven presupposed reasons and one open-end reason for why students like using videos in class.

Reason 1: Using videos in class can inspire students' interest in learning

Reason 2: Using videos in class provides a real context for learning

Reason 3: Using videos in class helps students understand, memorize and concentrate

Reason 4: Using videos in class promotes awareness of intercultural communication

Reason 5: Using videos in class encourages classroom practice and promotes English ability

Reason 6: Using videos in class lights up the classroom atmosphere and performs activities

Reason 7: Using videos in class enlarges students' knowledge of English video stars

Students are asked to choose more than one alternatives in this question. Figure 2 illustrates students' preferences for these reasons. 62 students choose Reason 1 (Using videos in class can inspire students' interest in learning), which makes it the dominant reason for why students like videos in class. 52 students believe that using videos in class lights up the classroom atmosphere and perform activities. These two reasons coming to the top is within the writer's expectation. However, only 22 students choose Reason 3 (Using videos in class helps students understand, memorize and concentrate), which is contrary to expectation. Jiang points out that audio-visual aids help students concentrate on the process of learning [6]. According to pedagogical psychology, if learners can concentrate while they are studying or being trained, their brain will have a most clear reflection of the content of what they are learning. Audio-visual aids of videos transfer vivid, clear and complete information into students, which creates an exciting point on their brain. High level of concentration inspires students' desire of learning actively [7].

Then why do the results contradict previous research findings? Students do not think that using videos in class helps them understand, memorize and concentrate better. "I like watching videos in class, but I do not think it helps me to improve my understanding. Because I can only understand 70\% of the actor's lines and the bad thing is that teachers don't explain them to us." said one sophomore in the interview. The theory that using videos in class helps students understand, memorize and concentrate does work. However, in real classes the disadvantages of using videos often take dominance. Thus, the advantages are not fully realized according to the result of this questionnaire. The following parts why students dislike videos in class give more specific explanation to this problem. 


\subsubsection{Reasons against using videos in English classes}

$13 \%$ of the one hundred subjects think they dislike using videos as a teaching tool in their English classes. Similarly, their opinions vary in their choices of reasons. Figure 3 illustrates students' preferences for the reasons why they dislike using videos as a teaching tool in their English classes. In the questionnaires, the research designer gives six presupposed reasons and one open-end reason for why students dislike using videos in class.

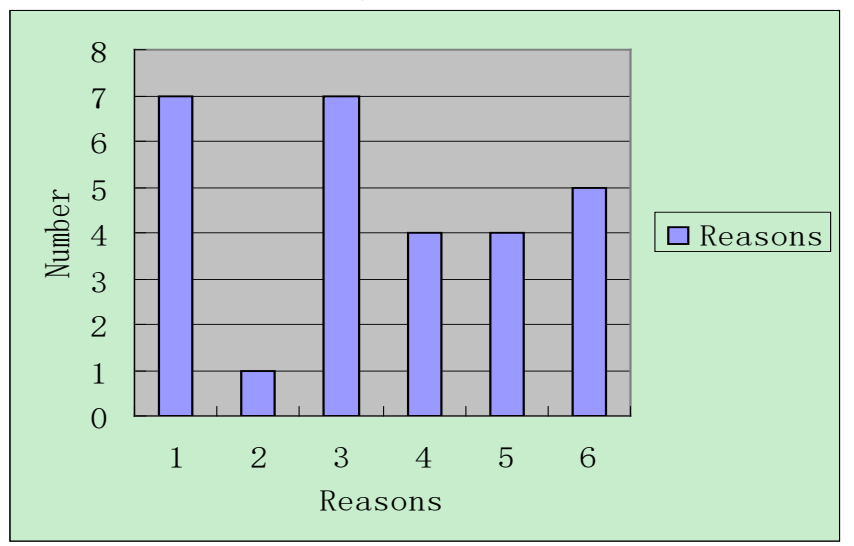

Figure 3. Reasons against using videos in the EFL classes

Reason 1: Teachers choose videos randomly without consideration

Reason 2: The subjects of videos are too old and cliché

Reason 3: Lack of background and other related information of the videos

Reason 4: Lack of explanation of difficult words and sentences

Reason 5: Lack of related and effective classroom activities

Reason 6: Lack of related and effective homework

Figure 3 shows that Reason 1 (Teachers choose videos randomly without consideration and clear purpose) and Reason 3 (Lack of background and other related information of the videos) are two most crucial ones that explain why students dislike using videos in their English classes. In the open-end alternative, there are some other reasons offered by students. "Watching videos in class is a huge waste of precious class time" "Teachers do not play the roles at all when we are watching videos" "Students only have fun from watching videos" "There is no difference between watching in class and in dormitory, so why should we waste time in class? Besides, it is not as comfortable as in dormitory".

Summerfield points out the possible negative effects of using videos in class [8]. Regarding English language teaching and learning, videos might misinform or distort the truth, and even lie; the experience they provide might be superficial; they might cause people to fear, dislike, or minimize human differences; some videos might reinforce ethnocentrism, reinforce a single perspective, or create or reinforce stereotype. Moreover, during the process of watching videos, students are easily distracted by the content of scenes and plot. It might be difficult to accomplish the planned language learning aim while students pay much less attention to the language itself [3]. Furthermore, using videos in class takes up so much time that other classroom activities cannot be fully performed. Besides, students will not have as many chances for thinking and discussing, which is one of the most important parts of their learning.

Most of the reasons why students dislike using videos in class are not substantial reasons, but are caused by the actual situation in classroom. This helps explain the conflict against former expectation based on audio-visual aids theory in the discussion of why students like using videos in 
class. Using videos in class actually helps students to understand, memorize and concentrate better. However, in real classes it is difficult to fully realize the advantages of using videos in class and the disadvantages often take dominance. This is the reason why students do not like using videos in class.

\subsection{Students' focus of attention}

Different students have different focuses when they are watching videos. English learners' classes aim at improving students' English skills. Using videos in class is one of the pedagogical approaches. Thus, knowing and adjusting students' focus becomes an important measure to make their learning more effective. Figure 4 illustrates the focus of attention when the 100 subjects are watching videos in class.

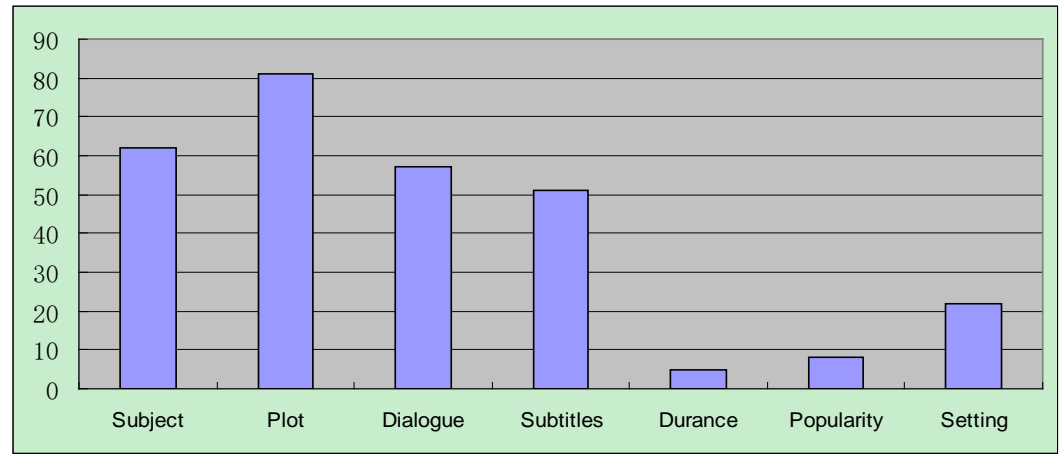

Figure 4. Students' focus of attention

81 students choose "plot" as their focus point while watching videos in class. 62 students choose "subject" as their focus point. "Dialogue" stands the third place having 57 choices. The forth one is "setting" (22) and the fifth is popularity (8), while only 5 students choose "durance" as their main focus. Obviously, students pay most attention to plot and subject; while durance and popularity of the video are students' least focused ones.

\subsubsection{Focus on plot and language in English classes}

According to Figure 4, students incline to pay most attention to the plot of videos. The plot is a series of significant events that happen in the video, which is dramatic and exciting. Naturally, students are easily attracted by the plot.

When asked what features a video should have when it is used in English class, 84 students choose the one with “dramatic and interesting plot". Figure 5 illustrates students' preferences for what features they think a video in class should have.

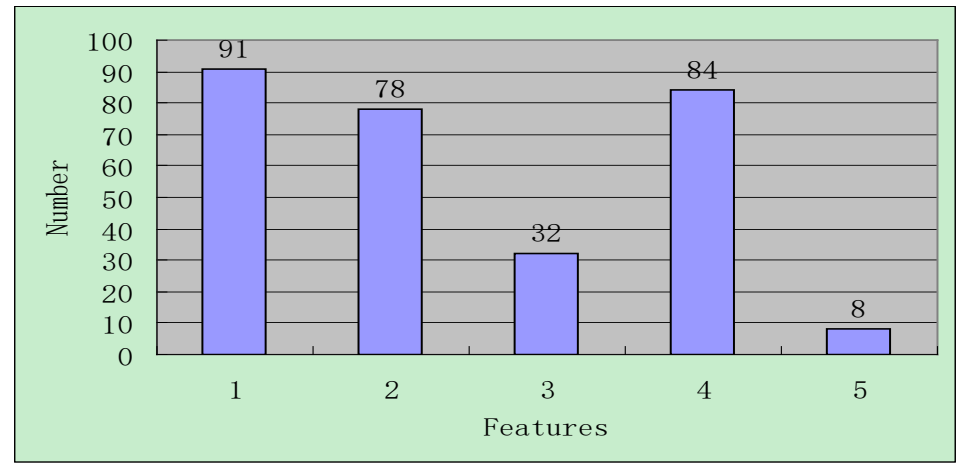


Figure 5. Features a video should have when being used in class

Feature 1: The one with clear dialogues and pronunciation

Feature 2: The one with language containing large amount of information

Feature 3: The one with content related to daily life

Feature 4: The one with a dramatic and interesting plot

Feature 5: The one with famous actors and directors

Figure 5 shows that students pay more attention to plot rather than language itself. As Guan states out, during the process of watching videos, students are easily distracted by the content of scenes and plot [3]. It might be difficult to accomplish the planned language learning aim while students pay much less attention to the language itself. However, students in class have many more missions than just for fun. It is the teachers' responsibility to guide students to accomplish the learn goal. Obviously, the teachers' influence is missing.

91 students choose the one with "clear dialogues and pronunciation" and 78 students choose the one with "language containing large amount of information". It shows that students still pay attention to language learning while watching videos in class. The awareness of learning is still very strong, but it needs teachers' guidance and help to change awareness into competence through appropriate practice.

\subsubsection{Students' preference for subject matters}

Videos compose a variety of subjects, such as education, history, romance, comedy, science and thriller, etc. Different subjects give viewers different experience of feelings. Their emotion and mood varies as the subjects change. They become happy, sad, angry, content, criticizing or praising. Different subjects have different power; however, not every subject is suitable for class.

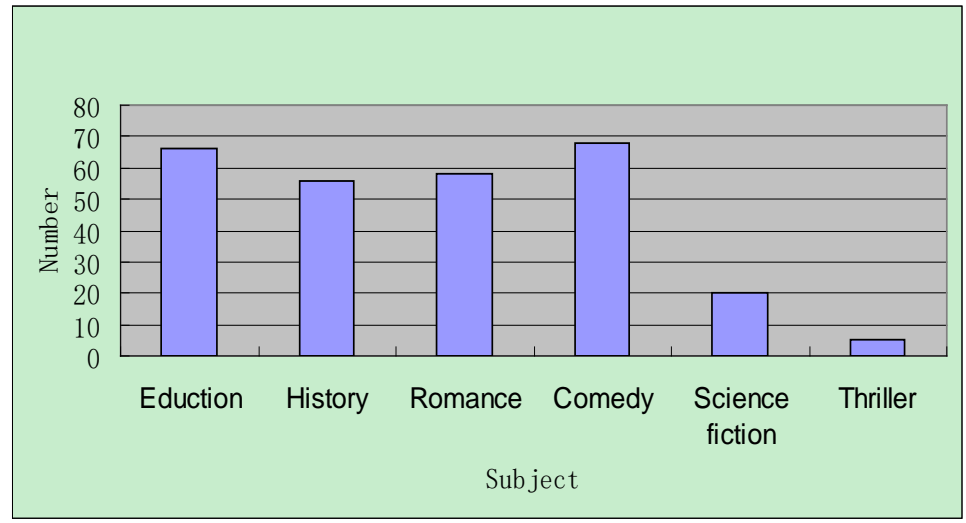

Figure 6. Suitable subjects of videos

Figure 6 illustrates students' preferences for subjects of videos. Comedy and education win the first two places, followed by romance and history, while science fiction and thriller are the least favorite subjects. It reveals that students incline to have fun at the same time of learning in class. Interesting and exciting subjects tend to be their favorite. Most students choose education, which shows that students are aware that watching videos is still a process of learning, although they believe that it is of limited help.

\subsubsection{Students' preference for durance}

In the question of students' focus of attention, only 5 students choose durance as their focus point 
when watching videos in class. However, durance actually plays an important role in the process of learning [9]. A further question is asked about what kind of durance students think is the most effective one. Figure 7 illustrates the percentage clearly.

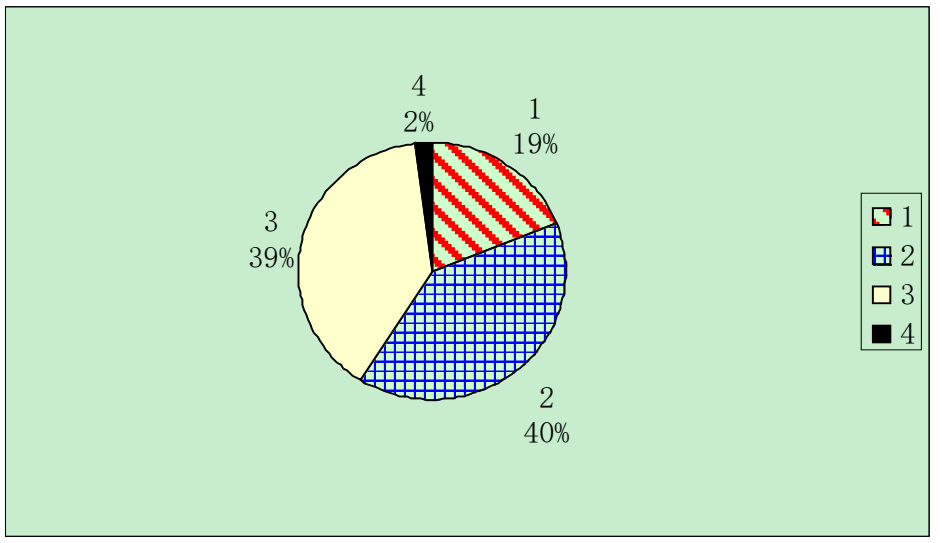

Figure 7. Most effective durance

Durance 1: Only playing sections of a video

Durance 2: Playing a complete video

Durance 3: Repeating some important sections after playing the complete video

Durance 4: Other opinions

$40 \%$ of the subjects think playing the complete video is the most effective durance. $39 \%$ of the students believe repeating some important sections after playing the complete video. 19\% of the students prefer only playing some classic sections and then performing related classroom activities. $2 \%$ of them have other opinions. "I think we should watch the complete video by ourselves before class. In class we only watch some sections, so then we will have more time to discuss and perform." One student writes this answer on the questionnaire. Actually class time is so limited that it is almost impossible to watch the complete video and then perform related activities, let alone repeat some sections. Thus, watching the complete video before class saves much precious class time. With the knowledge of the video, classroom activities can be very effective.

\subsubsection{Students' preference for subtitles}

One unique feature of videos is that there are subtitles of different languages. When watching videos, subtitles are the printed version of the spoken texts for the viewers to get better understanding. With the development of Internet, it is convenient to find different kinds of subtitles, such as English, Chinese and bilingual ones. Then, which kind do students think is the most suitable one when using videos in class? Figure 8 illustrates the results. 


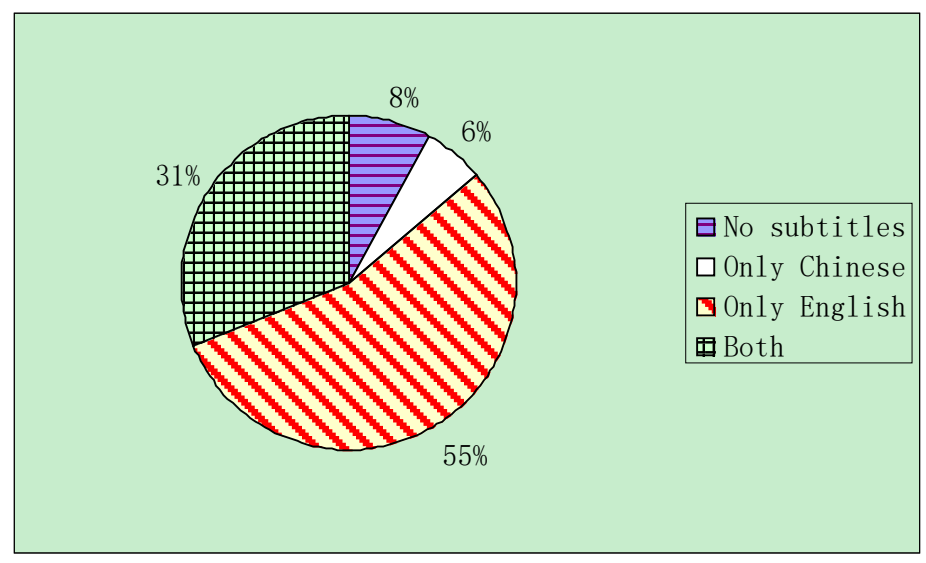

Figure 8. Students’ preference for subtitles

$55 \%$ of the students think that only English subtitles are suitable choice. $31 \%$ of the students believe that both English and Chinese subtitles should appear. 8\% of the students choose no subtitles and $6 \%$ choose only Chinese subtitles. The result reveals that students' awareness of language is strong while watching videos. They also give reasons for their answer.

According to the questionnaires, students who choose that they prefer no subtitles believe the most important reason is that watching videos without subtitles helps practice listening strategies. They can guess the meaning from the context, scene, facial expression and intonation, etc. The second most important reason is that they can use the most original materials without translation. Without subtitles they can also practice their endurance towards unknown words and sentences. It is a challenging opportunity to improve their listening ability.

Students who choose that they prefer watching videos with subtitles think that English and Chinese subtitles help enlarge their vocabulary and promote their speed of reading. The second reason which is chosen by 61 students is that subtitles help understand the difficult words, sentences and dialogues. 30 students think it helps them to catch up with the plot in a pressure-less environment.

In the interview, students give other answers to the question of choosing subtitles. "I think we need to watch the video sections three times. The first time it plays with no subtitles, second time with English subtitles and Chinese subtitles for the last.”

\section{Conclusion}

The present research studies students' attitudes and perspectives towards using videos in the EFL classes. The learner findings of the study can be summarized as follows: First, most of the students like using videos in class and they think it helps them improve listening, speaking, reading, writing and translating skills. However, in real class the disadvantages of using videos often take dominance and the advantages are not fully realized. Second, students pay more attention to plot rather than language itself. Their preferences for subjects, durance and subtitles show that they are aware of the learning process while watching videos in class, however, their awareness is not strong enough. It needs teachers' guidance and help to change awareness into competence through appropriate practice. With the conclusion of this paper, teachers may know better about the needs of students so that using videos as a teaching tool in class could be more effective. One of the major implications of this study is that instructors' leading and guiding role is of crucial importance when videos are used in class. In a video assisted class, instructors should take the role of an advocate, 
designer, organizer, leader, explainer, assessor, operator as well as researcher. The efficiency of using video as a teaching tool in English class relies on the roles teachers are playing. All activities should be set aiming to enhance students' listening, speaking, reading, writing and translating skills. Teachers are the leaders of a class who controls the processing pace, adjusts atmosphere and creates opportunities for students to practice. After the activities, it is very important that teachers give helpful and appropriate assessment. Students need help to adjust their learning process and results. With appropriate activities, using videos as a teaching tool in class can yield the greatest returns on the investment of time and energy. It requires teachers' careful preparation before class, as well as students' cooperation in and after the class.

This research has limitations. The number of the subjects is relatively small compared with the total number of Chinese English learners and they may not be the best representatives. Besides, this thesis only conducts a general research which does not deal with specific details in using videos as a teaching tool. Thus, for future researchers, they could do researches to find out how videos help students in their listening, speaking, reading, writing and translating specifically.

\section{Acknowledgements}

The authors gratefully acknowledge the financial support from Fundamental Research Funds for School of Foreign Languages \& Cultures of Xiamen University.

\section{References}

[1] Champoux, J. 2003. At the Movies: Cinema in Our Classrooms. Paper presented at Education Forum: Society for Industrial and Organizational Psychology Conference, Orlando, Florida.

[2] Champoux, J. 1999. Film as a teaching resource. Journal of Management Inquiry. 8 (2), pp. $240-251$.

[3] Guan, L. 2007. The role of original DVD movies using in college English teaching: advantages and disadvantages. Movie Review, No. 12, pp. 64.

[4] Zhao, F. 2006. Using Film as A Means to Develop Intercultural Competence for China's EFL Students. Unpublished Master's Degree dissertation, Shanghai Foreign Languages University.

[5] Hu, J. 2006. Present situation and strategies of movie teaching. Movie Review, No. 20, pp. 65.

[6] Jiang, S. 1996. Movie teaching and developing intercultural competence for students. Media in Foreign Language Instruction, No. 3, 1996. pp. 12.

[7] Sheng, J. 1998. Theories and advantages of audio-visual teaching. Media in Foreign Language Instruction, No. 2, 1998. pp. 19 20.

[8] Summerfield, E. 2004. The Power of Movies. 2 November 2007. 26 March 2018.

$<$ http://www.culturosity.com/articles/powerofmovies.htm>

[9] Zhang, D. \& Li, Y. 2004. Context Theory and Audio-visual Teaching of English. Media in Foreign Language Instruction. No. 98. pp 13 15. 